\title{
Difference in Thickness Between Right Ventricle and Left Ventricle of Adult Human Heart: A Cadaveric Study
}

\section{Kalpana Thounaojam ${ }^{1}$, Keisam Anupama Devi ${ }^{2}$, Joyce Tunglut ${ }^{3}$.}

${ }^{*}$ Associate Professor, Department of Anatomy, Jawaharlal Nehru Institute of Medical Sciences, Imphal, Manipur, India.

${ }^{2}$ Assistant Professor, Department of Anatomy, Jawaharlal Nehru Institute of Medical Sciences, Imphal, Manipur

${ }^{3}$ Demonstrator, Department of Anatomy, Jawaharlal Nehru Institute of Medical Sciences, Imphal, Manipur, India.

\section{ABSTRACT}

Background: The left ventricle is longer and narrower than the right ventricle, extending from its base in the plane of the atrioventricular groove to the cardiac apex. The wall of the left ventricle is three times thicker $(8-12 \mathrm{~mm})$ than those of right ventricle. The wall of the right ventricle is relatively thin $(3-5 \mathrm{~mm})$, the ratio of the thickness of the two ventricular walls usually being 1:3. Hypertrophic cardiomyopathy is characterized by myocardial wall thickening, particularly a disproportionate thickening of the interventricular septum in comparison with the posterior wall. An athlete's heart may physiologically hypertrophy but in a uniform fashion. The objective of the study is to determine the thickness of wall of right and left ventricle of adult human heart and ratio of thickness of right and left ventricle.

Materials and Methods: Adult human hearts were procured from the specimens preserved in Anatomy Department of Jawaharlal Nehru Institute of Medical Sciences. A cross-sectional study was conducted on forty- four specimen of adult heart. The measurement of the right and left ventricular wall was done with digital vernier caliper. The measurements were done at three levels in both right and left ventricle: upper, middle and lower part.

Result and Conclusion: The ratio of the thickness of the wall of right and left ventricle is well known as 1:3. However, in our study we found the ratio as 1:1.4. We found the thickness of the right ventricle thicker than the normal thickness reported in previous studies. We wish to continue the study with a larger sample size.

KEY WORDS: Heart, Right ventricle, left ventricle, Thickness Ratio, Myocardium.

Corresponding Author: Dr Kalpana Thounaojam, Associate Professor, Department of Anatomy, Jawaharlal Nehru Institute of Medical Sciences, Imphal, Manipur, India.

E-Mail: kalpanathounaojam@yahoo.in

Access this Article online

Quick Response code

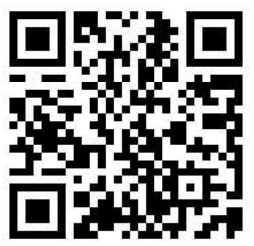

DOI: $10.16965 /$ ijar.2021.165

Journal Information

\section{International Journal of Anatomy and Research}

ISSN (E) 2321-4287 | ISSN (P) 2321-8967

https://www.ijmhr.org/ijar.htm

DOI-Prefix: https://dx.doi.org/10.16965/ijar

\section{(c) ET-No-sh}

\section{Article Information}

Received: 30 Aug 2021

Peer Review: 30 Aug 2021

Revised: None
Accepted: 05 Oct 2021

Published (O): 05 Dec 2021

Published (P): 05 Dec 2021

\section{INTRODUCTION}

Heart is a muscular pump that distributes blood to all parts of the body so as to provide the body parts with oxygen and nutrients. The human heart consists of four chambers viz., right atrium, right ventricle, left atrium and left ventricle. The right ventricle receives from the right atrium and pumps the deoxygenated blood to the lungs. The left ventricle pumps oxygenated blood to the rest of the body [1]. The outline of the heart as projected on the anterior chest wall in various subjects, during quiet respiration, may be conveniently classified into one of three general types which 
merge into one another: (a) the oblique, which is the most usual, (b) the horizontal, and (c) the vertical. These types tend to be related to the general body build and in particular to the position of the diaphragm. The horizontal heart tends to occur with a high diaphragm and a short broad trunk, the vertical with a low diaphragm and a slender trunk [2].

The left ventricle is longer and narrower than the right ventricle, extending from its base in the plane of the atrioventricular groove to the cardiac apex. The wall of the left ventricle is three times thicker $(8-12 \mathrm{~mm})$ than those of right ventricle [1]. The wall of the right ventricle is relatively thin $(3-5 \mathrm{~mm})$, the ratio of the thickness of the two ventricular walls usually being 1:3 [1].

The heart has four borders. The right border of the heart is formed by right atrium. The inferior border is formed by left ventricle and right ventricle. The left border is formed mainly by left ventricle with some contributions from the left atrium. The superior border is formed by right and left atrium with the great vessels

The effect of obesity on the heart is apparent as early as the second year of life. Obese children aged 2 years have a greater left ventricular mass compared with normal weight controls [3].

Hypertrophic cardiomyopathy is characterized by myocardial wall thickening, particularly a disproportionate thickening of the interventricular septum in comparison with the posterior wall. An athlete's heart may physiologically hypertrophy but in a uniform fashion [1].

Objective: The objective of the study is to determine the (i) thickness of wall of right and left ventricle of adult human heart. (ii) ratio of thickness of right and left ventricle.

\section{MATERIALS AND METHODS}

Adult human hearts were procured from the specimens preserved in Anatomy Department of Jawaharlal Nehru Institute of Medical Sciences. A cross-sectional study was conducted on forty- four specimen of adult heart. Gender was not considered. The heart was cut open along the right, inferior and left border of the heart. The superior border of the heart was kept intact so that the specimen can still be used for teaching purpose and other research works.

The measurement of the right and left ventricular wall was done with digital vernier caliper (Figure 3 ). The measurements were done at three levels in both right and left ventricle: upper, middle and lower part.

\section{RESULTS}

After measuring the thickness of the wall of the ventricles at three different levels, the mean thickness of the each ventricle were calculated. The mean thickness of wall of right ventricle was found to be $9 \mathrm{~mm}$. The mean thickness of left ventricle was found to be 13 $\mathrm{mm}$. The mean ratio of the thickness of right and left ventricle was found to be 1: 1.4 (Table 1, Figure 1, Figure 2).

The mean thickness of the lower part of the right ventricle is $6.6 \mathrm{~mm}$. The mean thickness of the lower part of left ventricle is $12.8 \mathrm{~mm}$. The mean ratio of the thickness of right and left ventricle was found to be 1: 1.9 (Table 1).

The mean thickness of the middle part of the right ventricle was $8 \mathrm{~mm}$. The mean thickness of the middle part of the left ventricle is 13 $\mathrm{mm}$. The mean ratio of the thickness of right and left ventricle in the middle part is $1: 1.8$ (Table 1)

The mean thickness of the upper part of the upper part of the right ventricle is $10 \mathrm{~mm}$. The mean thickness of the upper part of the left ventricle is $15 \mathrm{~mm}$, The ratio is $1: 1.5$ (Table 1 ).

The wall of both right and left ventricle is thickest in the upper part and thinnest in the lower part (Table 1)

Table 1: Chart showing the mean thickness of right and left ventricle.

\begin{tabular}{lccc}
\hline \multicolumn{1}{c}{ Thickness } & $\begin{array}{c}\text { Right ventricle } \\
\text { (in } \mathrm{mm} \text { ) }\end{array}$ & $\begin{array}{c}\text { Left ventricle } \\
\text { (in } \mathrm{mm} \text { ) }\end{array}$ & $\begin{array}{c}\text { Ratio of the } \\
\text { thickness (in } \mathrm{mm} \text { ) }\end{array}$ \\
\hline Overall Mean thickness & 9 & 13 & $01: 01.4$ \\
Mean thickness of the lower part & 6.6 & 12.8 & $01: 01.9$ \\
Mean thickness of the middle part & 8 & 13 & $01: 01.8$ \\
Mean thickness of the upper part & 10 & 15 & $01: 01.5$ \\
\hline
\end{tabular}




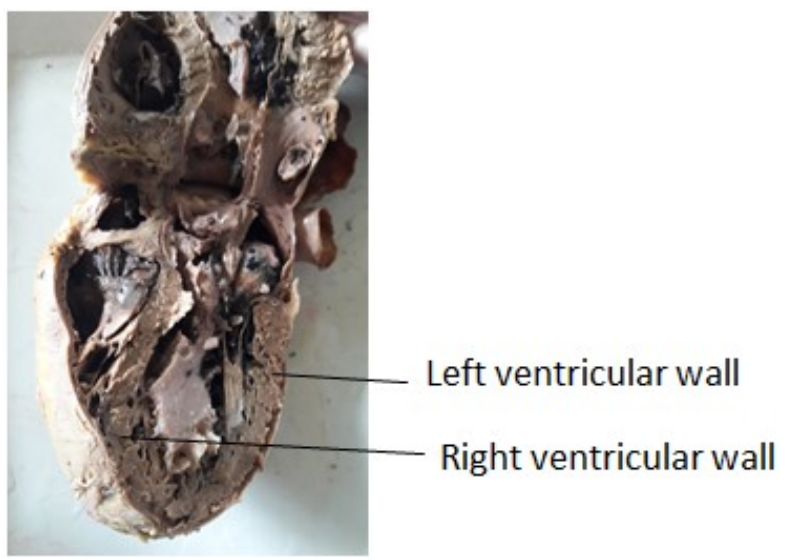

Fig. 1: Section of heart showing thickness of right and left ventricular wall.

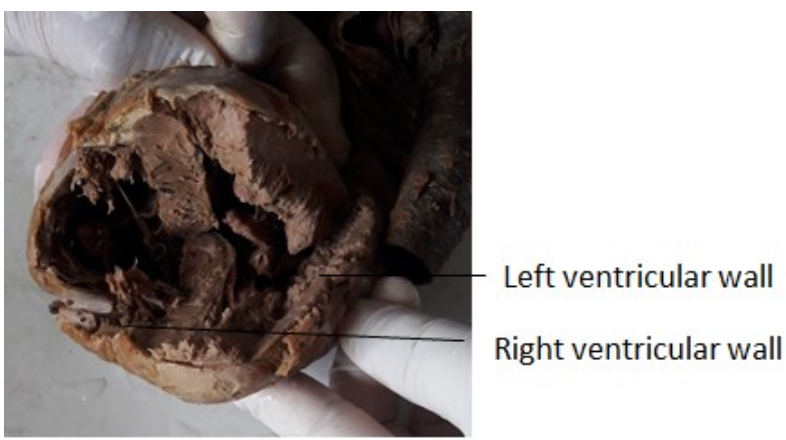

Fig. 2: A view of section of Heart from below.

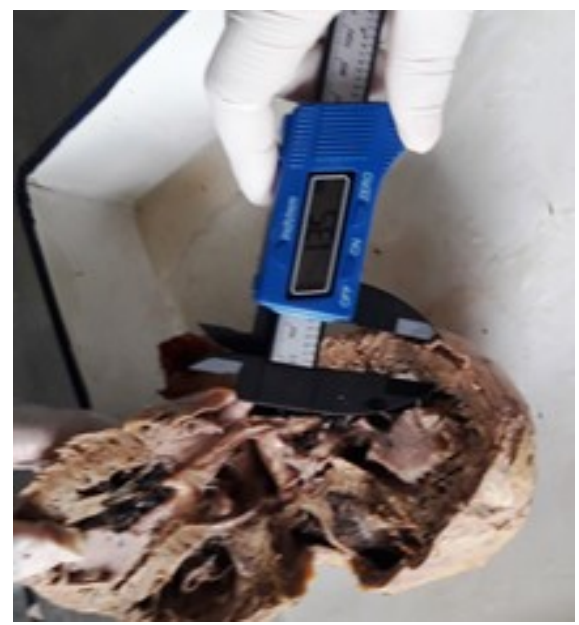

Fig. 3: Section of Heart showing the measurement of ventricular wall.

\section{DISCUSSION}

The difference in the size of the two ventricles in adult is well known and the ratio of right to left ventricular is $1: 3$, the reason being the difference in the resistance of the two circulations i.e., systemic and pulmonary circulation. However, in fetal life the difference in ventricular size remains unknown (4) However, to our surprise, the present study showed a varying result to this well-known ratio of the thickness of right and left ventricular wall. The mean ratio of the thickness of right and left ventricle was found to be 1: 1.4 in our present study. In fact, we could not find many studies on thickness of ventricles of adult normal heart.

After the age of 1 year, cardiomyocytes have reached their final number and changes in LVM reflect the growth of myocytes (hypertrophy) as a response to increased pressure or volume load [5].

Although growth during infancy may be influenced by feeding, the relation of coronary heart disease mortality to weight at one year is independent of method of feeding in infancy [6].

One link between undernutrition in late 30 gestation and persisting increase in left ventricular mass could be mediated through cardiovascular adaptive changes in utero [7].

When cardiovascular risk factors are present from childhood, they usually persist into adulthood and predispose children to an increased risk of cardiovascular events in adult life [8].

The RV wall is about $2-5 \mathrm{~mm}$ in thickness, $25 \pm 5 \mathrm{~g} / \mathrm{m} 2$ in weight, and mainly composed of deep and superficial muscle layers [9], In our study, the mean thickness of the right ventricular wall was found to be $9 \mathrm{~mm}$.

The muscular wall of the normal RV is usually 3 to $5 \mathrm{~mm}$ in thickness, but in conditions of pressure overload, the RV wall thickness may even exceed that of the LV [10] Our present study also showed a more than the usual thickness of right ventricular wall. This may be attributed to the adaptive changes of heart musculature.

The wall of the left ventricle $8-12 \mathrm{~mm}$ thick [1]. The mean thickness of left ventricle was found to be $13 \mathrm{~mm}$ in our present study. Due to the oblique position of the heart, the RV apex is inferior to the LV apex and at times, when the RV is conspicuous, the heart can appear to have a bifid apex [11].

When the pericardium is removed, the major part of the heart visible from the front is the ventricular mass. Here, the morphologically right ventricle occupies the greater part. The left ventricle appears only as a narrow slip along the left cardiac border. The shape of the heart is generally likened to a pyramid with a base and an apex. The apex points downward, 
forward, and to the left, whereas the base faces posteriorly and to the right [12].

The myocardium in patients with $\mathrm{HCM}$ is heterogeneously thickened and the fractional thickening and circumferential shortening of the abnormally thickened myocardium are reduced compared with healthy subjects [13]. In our study, the thickness of right ventricle and also of the left ventricle are not same at different levels. We found that the ventricular walls are thickest in the upper part, and thereafter, the thickness gradually decreases. The ventricular walls are most thin in the lower part. The differentiation between physiological left ventricular (LV) hypertrophy secondary to exercise and hypertrophic cardiomyopathy (HCM) is a complex and increasingly common clinical dilemma [14].

The wall of both right and left ventricle is thickest in the upper part and thinnest in the lower part according to our study.

\section{CONCLUSION}

The ratio of the thickness of the wall of right and left ventricle is well known as 1:3. However, in our study we found the ratio as $1: 1.4$. We found the thickness of the right ventricle more thicker than the normal thickness reported in previous studies. We wish to continue the study with a larger sample size.

\section{Conflicts of Interests: None}

\section{REFERENCES}

[1]. Standring S Jonathan D Spratt, Marios Loukas. Heart. Gray's Anatomy- The Anatomical Basis of Clinical Practice. $41^{\text {st }}$ edition.London : Churchill Livingstone, Elsevier, 2016: 994- 1023.

[2]. Hamilton WJ, Simon G, Ian Hamilton SG. The chest and back.Surface and Radiological Anatomy. Cambridge: W Heffer \& Sons Itd Baltimore: The Williams \& Wilkins Company; 1971: 101-189.
[3]. de Jonge LL, van Osch-Gevers L, Willemsen SP, Steegers E.A.P, Hofman A, Helbing WA, Jaddoe V.W.V. Growth, obesity, and cardiac structures in early childhood: the Generation R study. Hypertension 2011; 57: 934-40.

[4]. Daimei T, N. Damayanti D, Sinam V. Difference between the left and right ventricular thickness in fetal heart. IOSR Journal of Dental and Medical Sciences. 2014; 13(4): 21-24.

[5]. Kehat I, Molkentin JD. Molecular pathways underlying cardiac remodeling during pathophysiological stimulation. Circulation. 2010; 122: $2727-$ 2735.

[6]. Osmond C, Barker DJP, Winter PD, Fall CH, Simmonds SJ. Early growth and death from cardio- vascular disease in women. BMJ 1993; 307(6918):1519-24.

[7]. Dicke JM. Poor obstetrical outcome. Clinical obstetrics. ed Pauerstein CJ,. Edinburgh: Churchill Livingstone, 1987; 421-39.

[8]. Berenson GS. Childhood risk factors predict adult risk associated with subclinical cardiovascular disease. The Bogalusa Heart Study. Am J Cardiol 2002; 90: $3 L-7 L$

[9]. Wanga JMH , Raib R , Carrascoc M , Sam-Odusinac T, Salandyc S, Gieleckid J , Zuradae A, Loukasc M. An anatomical review of the right ventricle .Translational Research in Anatomy 2019; 17: 100049.

[10]. Warnes CA. Adult Congenital Heart Disease: Importance of the Right Ventricle J Am Coll Cardiol. 2009; 54 (21): 1903-1910

[11]. Muresian H. The clinical anatomy of the right ventricle. Clin. Anat. 2016;29(3):380-398.

[12]. Ho SY. Cardiac Anatomy and Physiology. Clinical Cardiac Pacing, Defibrillation and Synchronization Therapy $.5^{\text {th }}$ Edition. Elsevier, 2021: 3- 14.

[13]. Dong SJ, MacGregor JH, Crawley AP, McVeigh E, Belenkie I, Smith ER, Tyberg JV, Beyar R. Left ventricular wall thickness and regional systolic function in patients with hypertrophic cardiomyopathy. A three-dimensional tagged magnetic resonance imaging study. Circulation 1994; 90(3):12001209.

[14]. Maron BJ. Distinguishing hypertrophic cardiomyopathy from athlete's heart: a clinical problem of increasing magnitude and significance. Heart. 2005; 91:1380-1382.

How to cite this article:

Kalpana Thounaojam, Keisam Anupama Devi, Joyce Tunglut. Difference in Thickness Between Right Ventricle and Left Ventricle of Adult Human Heart: A Cadaveric Study. Int J Anat Res 2021;9(4):8116-8119. DOI: 10.16965/ijar.2021.165 